\title{
TRANSPORT AND FATE OF PESTICIDE IN UNSATURATED NONISOTHERMAL SOIL: EXPERIMENTAL AND NUMERICAL STUDIES FOR BROMOXYNIL OCTANOATE.
}

\author{
I. S. Al-Salamah \\ Department of Civil Engineering, College of Engineering \\ Qassim University, Saudi Arabia
}

\begin{abstract}
Transport of bromoxynil octanoate (3,5-dibromo-4-hydroxy-benzonitrile) and water were studied experimentally and numerically in closed soil columns. Bromoxynil and water content distributions in the soil columns were measured. A numerical model was developed based upon unsteady state movement of water, heat and nonvolatile organic compound (i.e., bromoxynil octanoate) for simulating the measured data. Loamy sand soil was moisturized then packed in sealed PVC columns $(0.10 \mathrm{~m}$ diameter and $0.3 \mathrm{~m}$ long). The average bulk density of soil columns was $1439 \mathrm{~kg} / \mathrm{m}^{3}$. The soil had initial water content of $0.113 \mathrm{~m}^{3} / \mathrm{m}^{3}$. The top $0.005 \mathrm{~m}$ - layer of soil column had $0.000272 \mathrm{~mol} / \mathrm{l}$ of bromoxynil, while the rest of soil column had zero concentration. The columns were buried vertically within a soil bin such that column surfaces were exposed to natural radiation of Qassim region, Saudi Arabia. Two soil columns lasted for 14 days. Both predicted and measured final soil water contents showed nonlinear distributions and similar trends. The water moved from the upper region $(0.05 \mathrm{~m}$ thick) toward the cold region at depth $0.1 \mathrm{~m}$. The measured and predicted soil water distributions in the lower layer (i.e., 0.1 to $0.3 \mathrm{~m}$ ) showed small changes. The predicted and measured bromoxynil concentrations behaved similarly in their trend. The upper $0.0-0.15 \mathrm{~m}$ was an active layer for degradation and movement of bromoxynil. The upper 0.0-0.05 m-region possessed lower concentration of bromoxynil while the succeeded region of 0.05 to $0.15 \mathrm{~m}$ possessed the highest concentration. Numerical simulation showed that increasing the mean temperature resulted more migration of water and bromoxynil from upper region toward lower region.

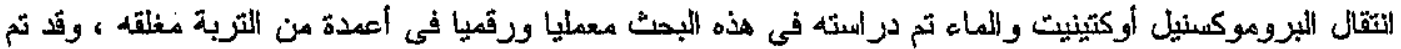

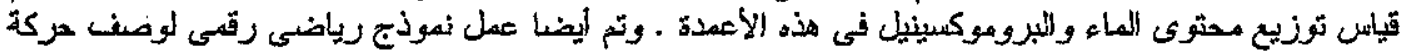

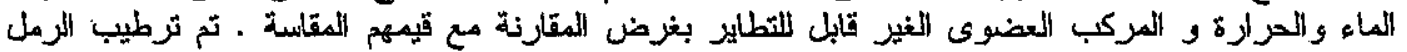

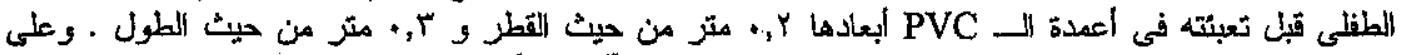

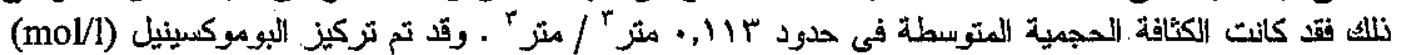

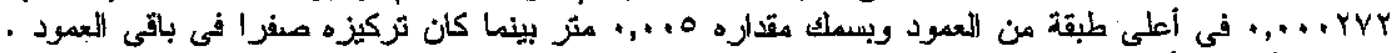

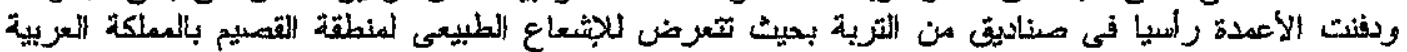

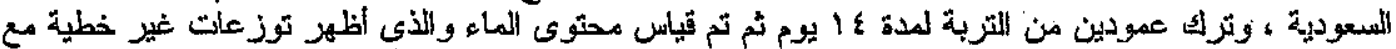

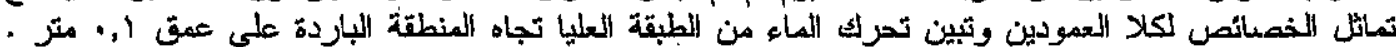

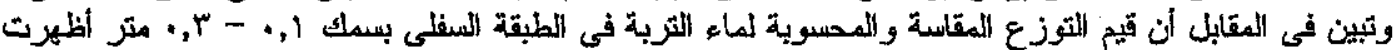

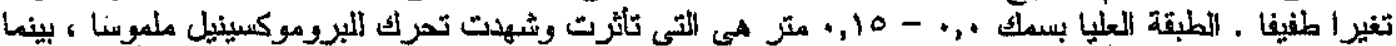

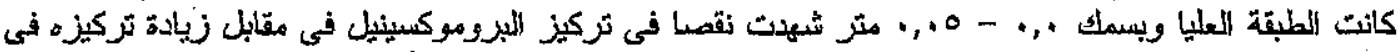

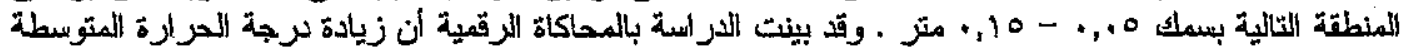

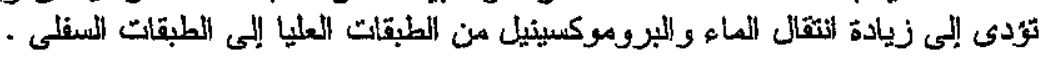

Keywords: bromoxynil octanoate; water movement; pesticide transport; modelling; simulation.

\section{INTRODUCTION}

Pesticides are widely used in agriculture to control a variety of organisms and weeds that damage crops. More than six hundreds types of agrochemicals are used around the world (Miyake et al., 1999). They provide unquestionable benefit for agricultural production; consequently, low amounts of some residues may persist in the food supply, air, water and soil. These residues could create potential chronic toxicity and in some cases, acute toxicity (Ekström et al., 1996, Osman and Al-Rehiayani, 2003). Bromoxynil (3,5-dibromo-4-hydroxybenzonitrile) as the octanoate ester is one of the agrochemicals (herbicide) widely used for controlling broad leaf weeds in cereal crops (Environment Canada,1986). The bromoxynil was ranked high with respect to potential for groundwater contamination in 
an agriculture Canada survey (Agriculture Canada, 1986). In general, the agrochemicals have different fates after their application. Some may be lost to the atmosphere by volatilisation (or evaporation), particularly those have high vapour pressure (Nassar et al., 1999a). Some others can be bounded to the soil components such as clay and organic constitutes (Salama et al., 2001). The bromoxynil octanoate is a good reactive with clay and organic components. The sorption coefficient per unit mass of organic carbon in soils $\left(\mathrm{K}_{\mathrm{oc}}\right)$ for bromxynil octanoate showed a wide variation among studies, possibly reflecting the varying nature of organic materials present in soils. For example, $\mathrm{K}_{\mathrm{oc}}$, ranged from 10 (Salama et al, 2001) to $18 \mathrm{Kg} / \mathrm{m}^{3}$ (Lyman et al., 1990). The bromoxynil octanoate can be degraded or transformed in soils. Biodegradation experiments showed a high mineralization of bromoxynil octanoate (Collins, 1973) in soil. Similarly, the main degradation and transformation pathways of bromoxynil octanoate in soil were mineralization and formation of bound residues (Rosenbrock et al., 2004). It broke down in the environment by photolytic degradation, abiotic hydrolysis and microbial-mediated metabolism under both aerobic and anaerobic conditions. The degradation of bromyxnil is function for several factors. One of these factors is $\mathrm{pH}$. Respective half-lives of 34.1, 11.5 , and 1.7 days were reported for Bromoxynil octanoate at $\mathrm{pH}$ of 5,7 and 9 . So, the half-life of bromoxynil decreased as soil $\mathrm{pH}$ increased. In two field experiments, half-lives were 14 days at a site in California. Bromoxynil has a low persistence in soil. In sandy soil, the half-life is about 10 days (Kidd and James, 1991 and Gordon and Pullin, 2006). Similar results are reported in Canada (Worthing, 1983).

Soil with high-saturated hydraulic conductivity can lead to ground water pollution by the bromoxynil octanaote. (Kookana et al., 1997) studied the sorption coefficient in different Australian soils. They reported that the sorption coefficients for pesticides were much lower in subsoil than in surface soils; in some cases they were negligible in subsoil. This suggests that in such soils, once the pesticide leaches beyond the top $50-100 \mathrm{~cm}$, it can move with the water-front with little retardation through sorption.

Since the agricultural sector is the largest for consuming the bromoxynil octanoate, we need to understand the fate and transport of this herbicide in the soil. Therefore, understanding the mechanisms of movement of the Bromoxynil can lead to better management. According to the literature cited above, bromoxynil movement in soil has rarely been studied experimentally under unsaturated nonisothermal conditions. The research project encompassed greenhouse and theoretical analyses. Therefore, the first objective of this study is to perform nonisothermal experiments under natural radiation of Al-Qassim region, Saudi Arabia to observe water, and bromoxynil octanoate (r:on-volatile) transfer in unsaturated soil. Here, we ust the Nassar and Horton (1999b) formulation for non-volatile organic chemicals without inclusiori of inorganic solute transport and osmotic effects. So, the second objective is to test a model based upon the unsteady state transfer of water, heat and non-volatile organic solute in unsaturated nonisothermal soil conditions against the greenhouse experimental data.

\section{MATERIALS AND METHODS}

\subsection{Experimental}

Soil materials were sampled from a surface layer $(0.0$ $0.3 \mathrm{~m}$ depth) from the Agriculture and Veterinary Collage farm, Qassim University, Al-Qassim. The soil materials were air-dried and ground to pass a $2-\mathrm{mm}$ sieve. The soil texture was loany sand $(83.96 \%$ sand, $14.82 \%$ clay and $1.22 \%$ silt) naterials. In addition, water-characteristic curve was measured for the site soil using pressure plate extractors (Dane and Hopmans, 2002) in a matric potential range 0 to $1500 \mathrm{kPa}$. Portion of the material was wetted with distilled water to obtain an initial volumetric water content of $0.113 \mathrm{~m}^{3} / \mathrm{m}^{3}$. The moistened soil was covered and stored at $20^{\circ} \mathrm{C}$ for? days. PVC cylinders $(0.1-\mathrm{m} \mathrm{ID}$ and $0.3-\mathrm{m}$ high) were closed at the bottom ends using epoxy-sealed PVO lids then packed uniformly with the moisturized soil. Two soil columns were packed at an average bulk clensity of $1439 \mathrm{~kg} \mathrm{~m}^{-3}$. A volume of $0.5 \mathrm{ml}$ of bromoxynil octanoate solution was injected in the top $0.005-n$ layer of each soil column to obtain $2.72 \times 10^{-7} \mathrm{~mol} / \mathrm{m}^{3}$ in soil solution as an initial concentration. Each soil column was tightly closed at its top end using whire plastic then buried vertically within a bare soil field with exposing the upper end to the natural atmosphere of Al-Qassim region on January 11,2007 . The soil temperatures at upper end of soil column were recorded four times a day ( $6 \mathrm{am}, 2,6$ and $12 \mathrm{pm})$. Meim and the amplitude of the recorded temperature were obtained. The two soil columns were removed and sectioned into seven ircrements. The length of increments was different. The soil of each increment was divided into two portions: a portion for water content and a portion for bromoxynil octanoate determinations. The soil water contents were determined gravimetrically in each increment. For bromoxynil determination, soil samples were extracted with $20 \mathrm{rnl}$ of acetone for 24 hrs in shaker at room temperature then analysed by High Performance Liquid Chronıatography (HPLC) (Falqui-Cao et al, 2001). The percentage recoveries for the present study were satisfactory with a range of 90-108\% (Schuller et al, 1976). 


\subsection{Theoretical Analysis}

The formulation developed by Nassar and Horton (1999b) for organic volatile chemical was reduced to describe water, heat and bromoxynil octanoate transfer in a soil. The following theory assumes: matric water pressure head, gravity pressure head, temperature and non-volatile organic solute (bromoxynil) concentration gradients are driving forces for water, solute and heat transfers; the organic compounds can be associated with liquid and solid phases of the porous media; the liquid phase is mobile, but the solid phase is immobile; the transfer of organic compounds across liquid/solid is included using equilibrium assumptions at the interfaces, and the degradation of bromoxynil is described by a firstorder decay rate. The solute flow based upon the convection-dispersion equation (CDE) was used for describing the bromoxynil flow. The heat flow occurs by conduction and by convection of sensible heat and latent heat. The model can be used to predict spatial and temporal variations of water content, total concentration of non-volatile organic solute and temperature distributions within a porous medium. The finite differences scheme for the partial differential equations of heat, water, and organic solute transfers as described by Nassar et al. (1999a) was used in the model. A brief outline of theory presented below for completeness.

\subsubsection{Water flow}

The soil water flow equation for transient vertical flow based upon Darcy's law and the continuity equation is:

$$
\alpha_{1} \frac{\partial \theta}{\partial t}+\alpha_{2} \frac{\partial T}{\partial t}=-\Delta \cdot\left(\frac{q_{w}}{\rho}\right)
$$

where $\theta$ is water content $\left(\mathrm{L}^{3} \mathrm{~L}^{-3}\right) ; \mathrm{q}_{\mathrm{w}}$ is the soil water mass flux, $\left(M / L^{2} s\right) ; \rho$ is the density of soil solution $\left(\mathrm{M} / \mathrm{L}^{3}\right]$; and $\alpha_{1}$ and $\alpha_{2}$ are storage terms for water.

\subsubsection{Heat flow}

The nonsteady-state heat transfer equation in onedimension can be written as:

$$
K_{1} \frac{\partial T}{\partial t}+K_{2} \frac{\partial \theta}{\partial t}=-\Delta \cdot q_{h}
$$

where $q_{h}$ is the net heat flux $\left(\mathrm{M} \mathrm{L}^{2} / \mathrm{L}^{2} \mathrm{~T}^{3}\right) ; \mathrm{T}\left({ }^{\circ} \mathrm{C}\right)$ is temperature and the coefficients $\mathrm{K}_{1}$, and $\mathrm{K}_{2}$ are storage terms for heat.

\subsubsection{Pesticide flow and transformation}

The movement of miscible pesticide (i.e., bromoxynil octanoate) through a soil is assumed in the present study to be accomplished by chemical diffusion in the liquid phase in response to an aqueous concentration gradient and convection of the pesticide as the result of water flow in which the pesticide is dissolved. Total organic solute flux is:

$$
\mathrm{J}_{\mathrm{t}}=\mathrm{J}_{\mathrm{d}}+\mathrm{J}_{\mathrm{c}}
$$

Where $J_{t}$ is total pesticide flux $\left(M / L^{2} T\right), J_{d}$ and $J_{c}$ are diffusion and convection fluxes in the liquid phase, respectively.

The diffusion flux in a soil solution can be obtained from:

$$
J_{d}=-D_{p}(\theta) \frac{\partial C_{1}}{\partial z}
$$

where $D_{p}(\theta)$ is the diffusion coefficient of pesticide in porous media, $C_{l}$ is the concentration in the liquid phase $\left(M / L^{2}\right)$. The diffusion coefficient was described in details Nassar and Horton (1999a) and Lyman et al (1982).

The convective flux of a pesticide is usually represented as:

$$
J_{c}=-\theta D_{m}(q) \frac{\partial C_{1}}{\partial z}+q C_{1}
$$

where $D_{m}(q)$ is the mechanical dispersion coefficient that describes mixing between large and small pores. In the present study, the mechanical dispersion was neglected because the velocity of soil solution is small.

The total steady state solute flux in the liquid phase in a porous media, $\mathrm{J}_{\mathrm{t}}$ can be described as:

$$
J_{t}=-\theta D_{m}(q)\left(\frac{\partial C_{1}}{\partial z}\right)-D_{p}(\theta) \frac{\partial C_{1}}{\partial z}+q C_{1}
$$

The nonsteady-state equation for the pesticide transport can be written as: $\frac{\partial C_{t}}{\partial t}=-\frac{\partial J_{t}}{\partial z} \pm \Phi(7)$

where $C_{t}=\theta C_{l}+\rho_{b} C_{s}$, is the total pesticide concentration in liquid and sorbed phases $\left(M / \mathrm{L}^{3}\right), \rho_{b}$ is the bulk density of soil $\left(\mathrm{M} / \mathrm{L}^{3}\right), \mathrm{C}_{\mathrm{s}}=\mathrm{K}_{\mathrm{d}} \mathrm{C}_{\mathrm{l}}$ is the concentration of pesticide in the sorbed phase (M/M), $K_{d}$ is a partition coefficient $\left(\mathrm{L}^{3} / \mathrm{M}\right)$, and $\Phi$ is sources or sinks of pesticide (such as microbiological degradation) $\left(\mathrm{M} / \mathrm{L}^{3}\right.$ T).

The degradation potential of a given chemical is described with a half-life $\left(t^{1} / 2\right)$ value, assuming firstorder rate degradation. The half-life represents the combined influence of degradation in all phases. First-order degradation rate $\left(\mathrm{k}_{\mathrm{ref}}\right)$ is calculated using:

$$
k_{r e f}=\frac{\ln 2}{t}=\frac{0.693}{t}
$$

The half-life, $t$, for the bromoxynil octanaoate is 7 days in the present study. The decay coefficient $(\Phi)$ is described as a function of temperature, water content and soil depth (Boesten and van der Linden 1991) as:

$$
\Phi=f_{\mathrm{T}} f_{\theta} f_{2} k_{\text {ref }}
$$

where $f_{T}$ is a factor for the influence of soil temperature, $f_{\theta}$ is reduction factor for the influence of liquid water content, $f_{z}$ is reduction factor for the influence of the depth, and $\mathrm{K}_{\mathrm{ref}}$ is decay coefficient 
at a reference condition (i.e., those in soil collected from the plow layer at $20^{\circ} \mathrm{C}$ and at a matric pressure of $-1.0 \mathrm{~m}$ ).

$$
f_{T}=\exp \left(\zeta\left(T-T_{o}\right)\right)
$$

where $\xi$ is a function of $\mathrm{T}$

$$
\left.f_{\theta}=\min \left(l,\left(\theta / \theta_{\text {ref }}\right)\right) \beta\right)
$$

where $\beta$ is a constant, and $\theta_{\text {ref }}$ is the water content at a reference condition. The term $f_{z}$ is assumed to be unity in the present study.

The partition coefficient, $K_{d}$ can be estimated as

$$
\mathrm{K}_{\mathrm{d}}=\mathrm{K}_{\mathrm{oc}} \mathrm{f}_{\mathrm{oc}}
$$

Where $K_{\infty}$ is the organic carbon partition coefficient $\left(\mathrm{L}^{3} / \mathrm{M}\right)$ and $\mathrm{f}_{\mathrm{oc}}$ is the organic carbon fraction.

\subsubsection{Coupled organic chemical, water, and heat transport}

Three partial differential equations (Eqs. 1, 2, and 7) are presented. The equations should be solved simultaneously for understanding the mechanisms of energy and mass transfer in porous media. The equations can be used for describing the spatial and temporal variations of non-volatile organic chemical, water content, and temperature in porous media when the boundary and initial conditions, and the transport parameters are available.

\subsubsection{Initial and boundary condition}

The initial conditions associated with Eqs. (1), (2), and (7) are given by

$$
\begin{array}{lr}
\mathrm{T}(\mathrm{z}, 0)=\mathrm{T}_{\mathrm{i}}, \theta(\mathrm{z}, 0)=\theta_{\mathrm{i}}, & (0<\mathrm{z}<l), \\
\mathrm{C}_{\mathrm{h}}(\mathrm{z}, 0)=\mathrm{C}_{\mathrm{o}} & (0<\mathrm{z}<0.005 \mathrm{~m}), \\
\mathrm{C}_{\mathrm{l}}(\mathrm{z}, 0)=0.0 & (0.005<\mathrm{z}<\mathrm{l}),
\end{array}
$$

where $l$ is soil column length (m).

The temperature boundary conditions at upper end of the closed soil columns in Fig. 1 can be described by

$$
\begin{array}{ll}
\mathrm{T}(0, \mathrm{t})=\mathrm{T}_{\mathrm{m}}+\mathrm{A}\left(\sin \frac{2 \pi t}{24}\right) & \mathrm{t}>0 \\
T(l, t)=T_{c} & \mathrm{t}>0
\end{array}
$$

where $T_{m}$, and $A$ are the mean and amplitude temperatures at the upper boundary, respectively, and the $T_{c}$ is temperature at the bottom boundary, respectively. Figure 1 shows the results of calculated diurnal variation of soil temperature based upon the mean and amplitude temperatures. The calculated diurnal temperatures were used as the upper boundary temperatures.

The boundary conditions for water and solute are given in terms of net mass fluxes by

$$
\begin{aligned}
& \left(q_{l}+q_{v}\right)(0, t)=0, n_{c}(0, t)=0, q_{0}(0, t)=0 \quad t>0 \\
& \left(q_{w}\right)(l, t)=0, \quad J_{t}(l, t)=0 \quad t>0
\end{aligned}
$$

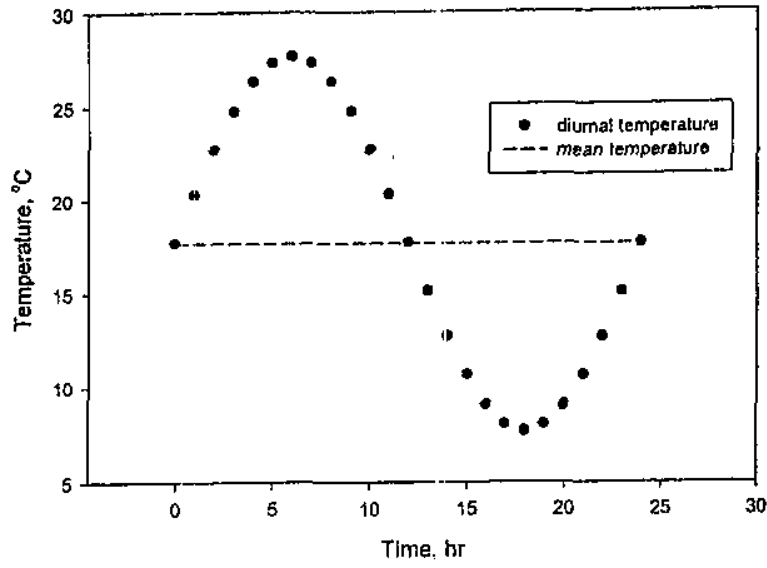

Fig. 1 An average diumal temperature at the top of soil colunin.

\subsubsection{Soil parameters and characterization}

Figure 2 shows the water-characteristic curve for the loamy sand soil used in the present study. The water characteristic curve was described by using Campbell's function (1974) as

$$
\psi_{m}^{\prime}=\psi_{e}\left(\theta / \theta_{s}\right)^{-b}
$$

where $\mathrm{b}$ and $\Psi_{\mathrm{e}}$ are fitting parameters, and $\theta_{\mathrm{s}}$ is saturated volumetric water content. Equation (16) is fitted to the measured $\theta$ for determining $\mathrm{b}$ and $\Psi_{\mathrm{e}}$. The coefficients of the function, $\Psi_{e}$ and $b$, are shown in Table (1). The unsaturated bydraulic conductivity, $\mathrm{K}(\theta)$, was estimated from knowledge of saturated hydraulic conductivity, Ks as following (Campbell, 1974):

$$
K(\theta)=K_{s}\left(\theta / \theta_{s}\right)^{2 b+i}
$$

Table 1 shows value for $K_{\mathrm{s}}$ of the loamy sand soil used in the present study.

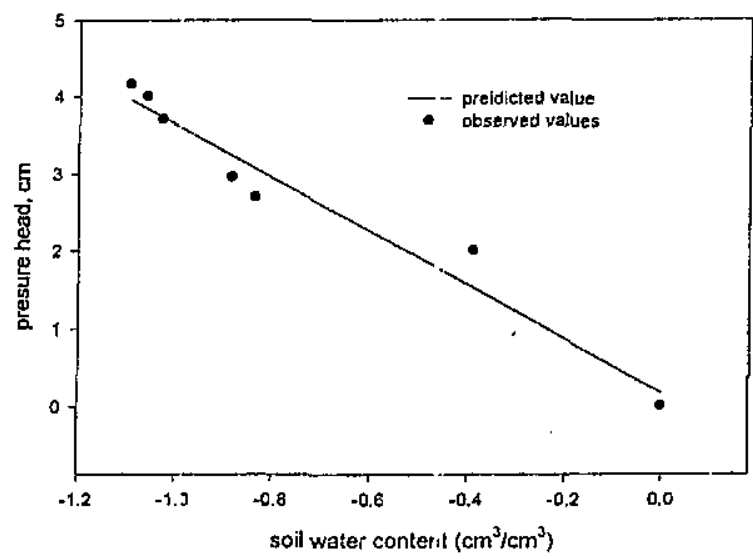

Fig. 2 Soil characteristics curve of floamy sand soil used in the present study. 
Table 1. Input characterization data for the presented

\begin{tabular}{ll}
\multicolumn{1}{c}{ model. } & Value \\
\hline Parameters & 1439.5 \\
\hline$\rho$ (bulk density) $\left(\mathrm{Mg} \mathrm{m}^{-3}\right)$ & 0.113 \\
$\theta_{\mathrm{i}}$ (initial water content $)\left(\mathrm{m}^{3} \mathrm{~m}^{-3}\right)$ & 0.459 \\
$\theta_{\mathrm{s}}(\mathrm{saturated}$ water content $)\left(\mathrm{m}^{-3} \mathrm{~m}^{-3}\right)$ & $1.98 \times 10^{-5}$ \\
$\mathrm{~K}_{\mathrm{s}}\left(\mathrm{m} \mathrm{s} \mathrm{s}^{-1}\right)$ & 14.82 \\
Clay, $(\%)$ & 83.96 \\
Sand $(\%)$ & 1.22 \\
Silt $(\%)$ & 18 \\
$\mathrm{~K}_{\mathrm{ac}}\left(\mathrm{m}^{3} \mathrm{~kg}^{-1}\right)$ & 0.057 \\
$\mathrm{~F}_{\mathrm{oc}}(\%)$ & $1.15 \times 10^{-5}$ \\
$K_{\mathrm{ref}}\left(\mathrm{s}^{-1}\right)$ & 0.15 \\
$\Psi_{\mathrm{e}}(\mathrm{kPa})$ & 3.46 \\
$\mathrm{~B}$ & 0.25 \\
$\zeta$ & 0 \\
$\mathrm{f}_{0}$ & 17.7 \\
$\mathrm{~T}_{\mathrm{m}}\left({ }^{\mathrm{C}} \mathrm{C}\right)$ & 10.0 \\
$\mathrm{~A}\left({ }^{\circ} \mathrm{C}\right)$ & 12 \\
$\mathrm{~T}_{\mathrm{c}}\left({ }^{\circ} \mathrm{C}\right)$ & \\
\hline
\end{tabular}

\section{RESULTS AND DISCUSSION}

\subsection{Predicted and Measured Soil Water Status}

The predicted and measured soil water content distributions in nonisothermal columns are shown in Fig.3. The predicted water content distributions are in agreement to the observed values in their trend. Small amount of water migrated from the upper zone of soil columns toward lower zones. This is expected because small temperature gradients exist beside the limited matric potential gradients. The predicted and observed soil water contents exhibited three distinguished zones. The first zone extended to $0.05-\mathrm{m}$ depth, the second zone was located between 0.05 and $0.10-\mathrm{m}$ depth and the third zone was below $0.10-\mathrm{m}$ depth. The first zone possessed the lowest water content and the second possessed the highest water content. It is obvious that water migrated from the upper zorie to the second zone. The initiative driving force for water movement is mainly temperature gradient those gradient derived water to migrate from the upper zone in vapour form followed by condensation in the second zone. It is expected that water movement in the upper zone mainly in vapour phase (Nassar et al., 1992). Condensation the water in the second could lead to water movement toward the first and third zone in liquid form under matric potential gradient. Similar results were reported by Nassar et al. (1992) and AlSalamah (2004). The third zone does not show much water migration since the temperature and matric potential gradient are limited. Several researchers found that temperature gradient has great effect on water flow Globus (1983) and Nassar et al (1992). So, the developed model was used to simulate the water contents under two mean temperatures $\left(15\right.$ and $\left.20^{\circ} \mathrm{C}\right)$.

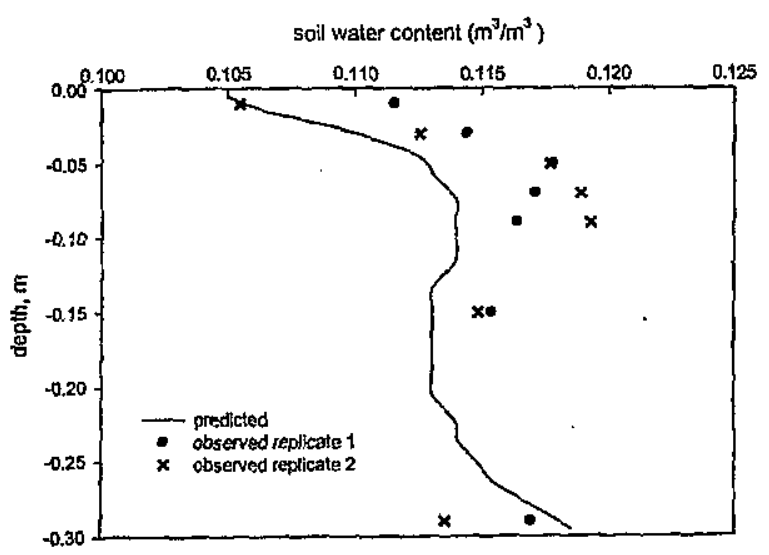

Fig. 3 Observed and predicted soil water contents.

The simulated data are shown in Fig. 4. It is obvious from the simulated soil water distributions that water movement from the upper zone of the soil column increased toward the lower zone as the mean temperature increases. Those increases in water movement are attributed to increasing the water transport coefficients as resulted from the temperature increases. Those coefficients are the soil hydraulic conductivity and thermal water diffusivity (Nassar and Horton, 1997).

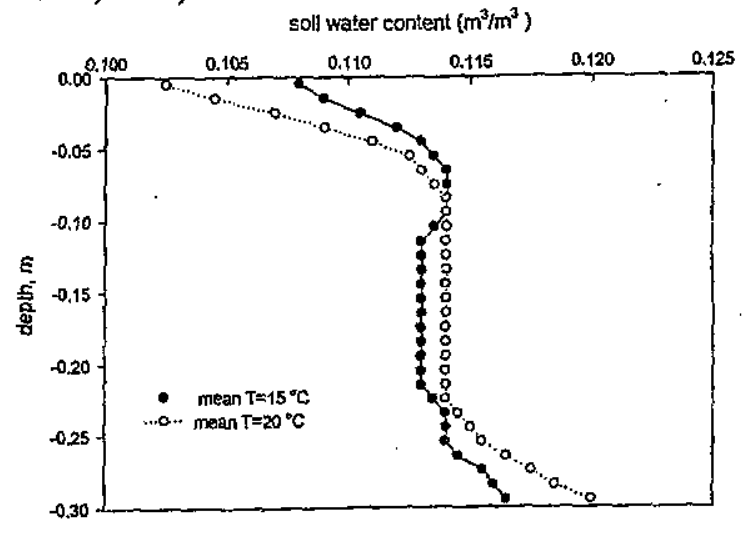

Fig. 4 Predicted soil water content under two different mean temperatures.

\subsection{Predicted and Measured Bromoxynil Octanoate Concentration:}

Measured and predicted Bromoxynil octanoate concentrations are compared in Fig. 5. The predicted and observed concentrations are similar in their trends. Both show high concentration in the Jayer 0.05 to $0.10 \mathrm{~m}$. The bromoxynil concentrations decreased in the upper zone $(0.05 \mathrm{~m}$ depth) then increased in the second zone ( 0.05 to $0.10 \mathrm{~m}$ depth) followed by decreasing in the lower portion of the soil column. Decreasing the bromoxynil concentration in the upper zone could be attributed to its photolytic degradation, abiotic hydrolysis and microbial-mediated metabolism. (Rosenbrock et al., 2004). The upper zone posses high temperature 
during the daytime, which increases photolytic degradation for the Bromoxynil. In addition, the initiative concentration of bromoxynil in the upper zone was the highest which drive partially the bromoxynil to move by diffusion mechanism. Under the condition of the present study, mass flow of solute is insignificant because the velocity of liquid water is small. The second zone of the soil column posses the highest concentration of bromoxynil because it has low temperature in comparison with the upper zone.

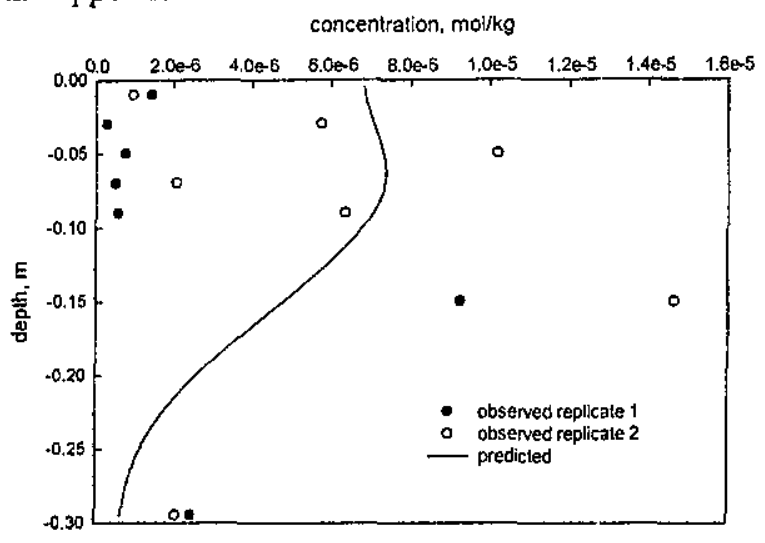

Fig. 5 Observed and predicted bromoxynil octanaote concentration.

Despite that good agreement between the measured and simulated water distributions, there is substantial disagreement between measured and simulated bromoxynil octanoate. One reason for the disagreement could due to the assumption that degradation of total pesticide obeys first-order kinetics. Similar results were reported by Wagenet et al (1989) for simulation of DBCP (1,2-dibromo-3chloro-propane). In addition, the distribution coefficient $\left(\mathrm{K}_{\mathrm{d}}\right)$ of bromoxynil octanoate is high (18 $\mathrm{m}^{3} / \mathrm{kg}$ ). Since the $K_{d}$ in the present study is high, most of the bromoxynil octanoate exists in the absorbed phase, which reduces its movement with mass flow of water. The total measured and predicted bromoxynil octanoate concentration means were $4.10018 \times 10^{-6}$ and $4.38967 \times 10^{-6} \mathrm{~mol} / \mathrm{Kg}$ of soil, respectively. In comparison with an initial bromoxynil octanoate of $1.89 \times 10^{-4} \mathrm{~mol} / \mathrm{Kg}$ of soil in the first $0.005 \mathrm{~m}$ layer, a great amount of bromoxynil octanoate degraded after 14 days. The favourable fate of a pesticide is a combination of fast degradation and strong adsorption to soil. The most sensitive parameters of pesticide models are related to the sorption and degradation of the compounds to be studied (Autio et al., 2004). Those authors reported that bromoxynil octanoate could be classified as immobile if the sorption coefficient, $\mathrm{K}_{\text {foc }}$, calculated from Freundlich's equation, exceeds $5 \mathrm{~m}^{3} / \mathrm{kg}$.

Effect of soil temperature on the fate of bromoxynil octanaote was studied numerically in the present study. The calculated concentrations of bromoxynil octanoate are shown in Fig. 6. As the mean temperature increased from 15 to $20^{\circ} \mathrm{C}$, the concentrations decreased in the upper layer drastically. The concentrations of bromxynil were one order of magnitude greater under mean temperature of $15^{\circ} \mathrm{C}$ in comparison to the mean temperature of $20^{\circ} \mathrm{C}$. It is concluded that effect of temperature on the fate of surface applied bromoxynil octanoate must be considered.

$$
\text { concentration, mol/kg }
$$
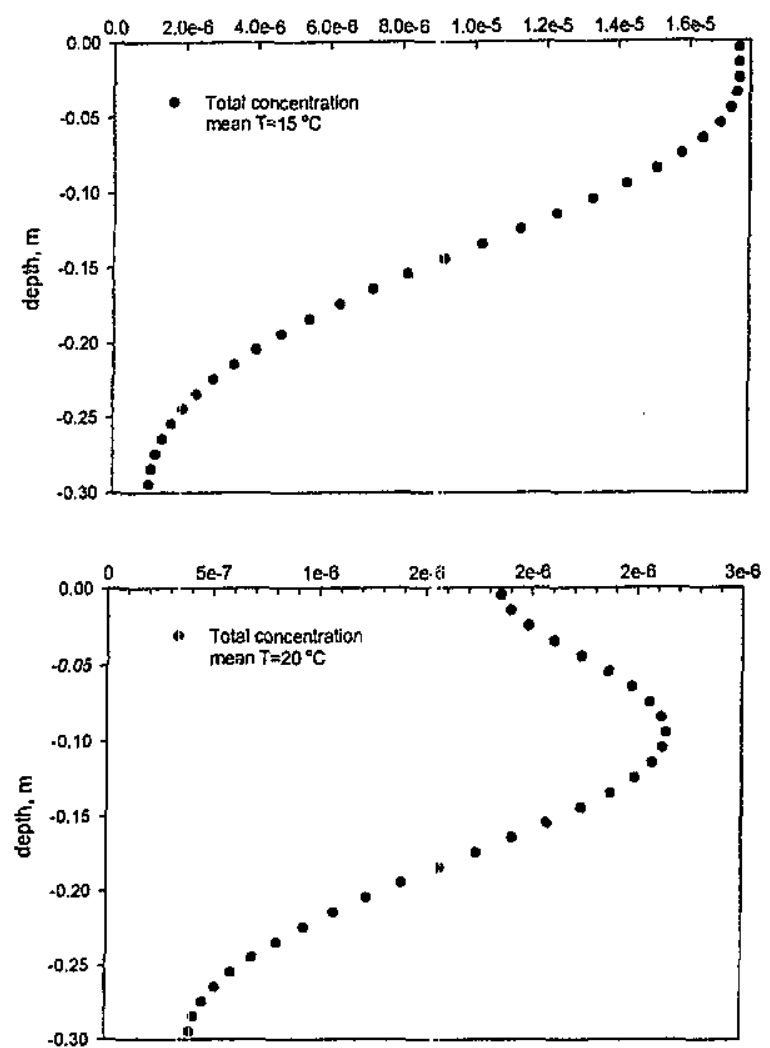

Fig. 6 Predicted bromoxynil octanaote concentrations under two different mean temperatures.

\section{CONCLUSIONS}

A greenhouse experiment was achieved for monitoring water and bromoxynil octancate transfer in closed loamy sandsoil columns. The soil columns were buried vertically in a bare soil field in Al-Qassium region, KSA. Bromoxynil octanoate solution was added to the upper layer $(0.005 \mathrm{~m})$ at experiment initiation. A numerical code was developeci based upon the partial diffusion equations of water, heat and non-volatile organic chemicals. The model was used to predict water and bromoxynil octancate concentrations and compared with measured. The predicted and observed water content trends were in agreement. Also, the predicted and observed romoxynil octanoate distributions a long the soil columns behaved similarly. Temperature has a great impact on water and bromoxynil octanate movement under the present study 
condition. The application of this model may be very useful for the development of remediation strategies to clean soil from bromoxynil octanoate compounds when nonisothermal conditions exist and the degradation and sorption coefficient are measured for the studied site. It should also be useful for monitoring bromoxynil octanoate redistribution at contaminated sites.

\section{REFERENCES}

[1] Agriculture Canada. 1989. Pesticide priority scheme for water monitoring program. Unpuplished report, pesticide directorate (1986). (puplished as backgrounder, No.89-01, issue, planning and priorties Division.

[2] Autio, S., K. Siimes, P. Laitinen, S. Ramo, S. Oinonen and L. Eronen. 2004. Asdorption of sugar beet herbicides to Finnish soils. Chemosphere, 55: 215-226.

[3] Boesten, J.J.T.I. and A. M. A. van der Linden, Modeling the influence of sorption and transformation on pesticide leaching and persistence, J. Environ. Qual. 20 (1991) 425435.

[4] Campbell, G. S.1974. A simple method for determining unsaturated conductivity from moisture retention data, Soil Sci. 117: 311-314.

[5] Collins, R.F. (1973). Perfusion studies with bromoxynil octanoate in soil, Pestic.Sci.4: 181192.

[6] Dane, J. H., and Hopmans, J.W. 2002. Pressure plate extractors. P. 688-690. In J. H. Dane and G. C. Topp (ed.). Methods of soil analysis. Part 4. physical methods. SSSA Book Ser. 5. SSSA, Madison, WI.

[7] Ekström, G., Hemming, H., Palborg, M. (1996). Swedish pesticide risk reduction 1985-1995: Food residues, health hazard and reported poisoning. Rev. Environ. Contam. Toxicol. 147: 119-139.

[8] Environment Canada/Agriculture Canada. 1986. Pesticide registrant survey, report. Commerecial chemicals Branch, conservation and protection, environment Canda, Ottawa.

[9] Falqui-Cao, C., Wang, Z., Urruty, L., Pommier, J.-J., and Montury, M. 2001. Focused microwave assistance for extracting pesticide residues from strawberries into water before their determination by SPME/HPLC/DAD. J. Agric. Food Chem., 49: 5092-5097.

[10]Globus, A. M. 1983. Physics of Non-Isothermal Soil Moisture Transfer. Hydrometeorological Publ., Leningrad (Russian) p.171-191.

[11]Gordon H. Ingram, Eileen M. Pullin 2006. Persistence of bromoxynil in three soil types. Pesticide Science 5:287-291.
[12]Kidd, H. and James, D. R., Eds. The Agrochemicals Handbook, Third Edition. Royal Society of Chemistry Information Services, Cambridge, UK, 1991 (As Updated). 10-2.

[13]Kookana, R.S., Phang, C. and Aylmore, L.A.G. 1997.Transformation and degradation of fenamiphos nematicide and its metabolites in soils. Australian Journal of Soil Research, 35: 753-761.

[14]Lyman, W. L., W. F. Reehl, and D. H. Rosenblatt, Handbook of chemical property estimation methods. McGraw-Hill Book Co., Inc., New York, N. Y., 1982.

[15] Lyman, W. J., W. F. Reehl, and D. H. Rosenblatt. 1990. Handbook of Chemical Property Estimation Methods. American Chemical Society. Washington, D.C.

[16]Miyake, Y., Koji, K., Matsuki, H., Tajima, R. (1999). Fate of agrochemical residues, associated with malt and hops. J. Am. Soc. Brew Chem. 57(2): 46-54.

[17]Nassar, I. N., L. Ukrainczyk, and R. Horton. Transport and fate of volatile organic chemicals in unsaturated, nonisothermal salty porous media :2. Experimental and numerical studies for benzene, J. Hazardous Materials, B69 (1999a) 169-185.

[18] Nassar, I. N. and R. Horton, Transport and fate of volatile organic chemicals in unsaturated, nonisothermal salty porous media :1Theoretical Development, J. Hazardous Materials, B69 (1999b) 151-167.

[19] Nassar, I. N., A. M. Globus and R. Horton 1992. Simultaneous soil heat, and water transfer. Soil Sci. 154:465-472.

[20]Nassar, I.N. and R. Horton, Heat, water, and solute transfer in unsaturated soil: I- Theoretical Development and transport coefficient evaluation, Transport in Porous Media, 27 (1997) 17-38.

[21] Osman, K.A., and Al-Rehiayani, S. (2003). Risk assessment of pesticide to human and the environment. Saudi J. Biol. Sci. 10(1): 81-106.

[22] Rosenbrock, P.; J.C. Munch, I.Scheunert, and U. DEoorfler (2004). Biodegradation of the herbicide bromoxynil and its plant cell wall bound residues in an agricultural soil. Pesticide Biochemistry and Physiology, 78: 49-57.

[23] Salama, R. B., Pollock, D. W. and Byme, J. D.: 2001, "Modelling pesticide and nutrient transport in the Gnangara Mound', in R. B. Salama and R. S. Kookana (eds), Agrochemical Pollution of Water Resources, Proceedings No. 104, Australian Centre for International 
Agricultural Research (ACIAR), Hat Yai, Thailand, 16-18 February 2000, pp. 138-144.

[24] Schuller, P.L., Horwitz, W., and Stoloff, L. 1976. A review of sampling plants and collaboratively studies method of analysis for aflatoxin. J. Assoc. Off. Anal. Chem. 59:13151343.
[25] Wagenet, R.J., J. L. Hutson and J. W. Biggar. 1989. Simulating the fate of a volatile pesticide in unsaturated soil: A case study with DBCP. J. Environ. Qual. 18:78- 84.

[26] Worthing, C.R. 1983. The pesticide manual- a world compendium. 7tt: edition. British Crop Protection Council. 